\title{
Computational tools for mechanistic discrimination in the reductive and metathesis coupling reactions mediated by titanium(IV) isopropoxide
}

\author{
AKSHAI KUMAR and ASHOKA G SAMUELSON* \\ Department of Inorganic and Physical Chemistry, Indian Institute of Science, Bangalore 560 012, India \\ e-mail: ashoka@ipc.iisc.ernet.in
}

\begin{abstract}
A theoretical study has been carried out at the B3LYP/LANL2DZ level to compare the reactivity of phenyl isocyanate and phenyl isothiocyanate towards titanium(IV) alkoxides. Isocyanates are shown to favour both mono insertion and double insertion reactions. Double insertion in a head-to-tail fashion is shown to be more exothermic than double insertion in a head-to-head fashion. The head-to-head double insertion leads to the metathesis product, a carbodiimide, after the extrusion of carbon dioxide. In the case of phenyl isothiocyanate, calculations favour the formation of only mono insertion products. Formation of a double insertion product is highly unfavourable. Further, these studies indicate that the reverse reaction involving the metathesis of $\mathrm{N}, \mathrm{N}^{\prime}$ diphenyl carbodiimide with carbon dioxide is likely to proceed more efficiently than the metathesis reaction with carbon disulphide. This is in excellent agreement with experimental results as metathesis with carbon disulphide fails to occur. In a second study, multilayer MM/QM calculations are carried out on intermediates generated from reduction of titanium(IV) alkoxides to investigate the effect of alkoxy bridging on the reactivity of multinuclear Ti species. Bimolecular coupling of imines initiated by Ti(III) species leads to a mixture of diastereomers and not diastereoselective coupling of the imine. However if the reaction is carried out by a trimeric biradical species, diastereoselective coupling of the imine is predicted. The presence of alkoxy bridges greatly favours the formation of the $\mathrm{d}, \mathrm{l}( \pm)$ isomer, whereas the intermediate without alkoxy bridges favours the more stable meso isomer. As a bridged trimeric species, stabilized by bridging alkoxy groups, correctly explains the diastereoselective reaction, it is the most likely intermediate in the reaction.
\end{abstract}

Keywords. DFT; hybrid methods; QM/MM; ONIOM; phenyl isocyanate; phenyl isothiocyanate and titanium(IV) alkoxide.

\section{Introduction}

The discovery of new catalytic processes depends to a great extent on serendipity. However, if one has to design and develop efficient catalytic processes, one has to understand the structure, property, reactivity and stability of the reactants, products and intermediates in the reaction. While the structure and reactivity of stable reactants and complex catalysts are often accessible through modern analytical tools, such experimental methods fail to provide reliable information about transient species involved in a reaction. Recent advances in theoretical studies, and enormous improvement in computational power, enable good estimations of the stability and structure of the species involved in chemical reactions. ${ }^{1}$ Significant inroads have been made into the understanding and prediction of intermediates in chemical transformations at a molecular level. ${ }^{2}$

*For correspondence
Earlier these methods were limited to only small molecules and could not be used to address complex systems such as proteins and biomolecules. ${ }^{3}$ However hybrid theoretical approaches have been formulated in recent times, where a large molecular system is divided into several subsystems or layers and each layer is treated at different levels of computational detail. ${ }^{4}$ In this approach, only the important part of the system which is directly involved in the reaction (such as bond making and bond breaking) is computationally evaluated with rigor. The other parts of the system which are not involved in bond making or breaking are handled using a lower and less demanding computational method. For instance, in the now well established multilayer QM/MM method, a complex molecule is divided into two parts, a high layer and a low layer. The high layer is computed in a quantum mechanical fashion whereas the low layer is computationally evaluated using molecular mechanics. ${ }^{5}$ These hybrid computational methods have been successfully employed in transition metal chemistry to study the influence of 
ligand environments on the catalytic activity of metal complexes. 'Real' molecules can now be treated more accurately and one can obtain more insight from these hybrid approaches. This allows one to correctly predict the influence of a ligand, tailor its environment around a metal centre, and generate more efficient catalysts. Computational methods have thus paved the way for advancements in catalysis in a rational way. ${ }^{6}$

There have been numerous reports where computational methods have been efficiently used to elucidate the reactivity patterns of group(IV) metal complexes. ${ }^{7}$ Jemmis and co-workers have employed molecular orbital studies using extended Huckel and MNDO methods to explain the difference in reactivity of group(IV) metallocenes towards bis acetylenes. ${ }^{8}$ Recently, the groups of Jemmis and Rosenthal have reported DFT studies at either the BP86 or the BS1:LANL2DZ levels to explain the reactivity of group(IV) metallocene alkyne complexes with carbodiimides. ${ }^{9}$ The formation of a five-membered heterometallacycloallenes in the reaction of metallocene alkyne complexes with carbodiimides has been postulated by DFT methods and confirmed by experimental techniques. The research group of Philip Mountford has extensively used DFT methods to explain the diversity in reactions of titanium hydrazido ${ }^{10}$ and titanium imido complexes ${ }^{11}$ towards insertion/cycloaddition of unsaturated substrates such as nitriles, heterocumulenes and olefins. Our group has carried out experimental and computational investigations on the insertion and metathesis reactivity of heterocumulenes and heteroalkenes mediated by group(IV) metal complexes. ${ }^{12}$ In these reports, the differences in reactivity of $\mathrm{Ti}$ and its congeners towards insertion and metathesis have been explained by DFT calculations carried out at the B3LYP/LANL2DZ level of theory. Several organic reactions mediated by $\mathrm{Ti}$ complexes have been computationally studied using QM/MM methods. ${ }^{13}$ More recently, we employed multilayer ONIOM calculations using QM/MM methods to satisfactorily explain the diastereoselectivity in coupling imines mediated by low valent titanium (LVT) reagents. ${ }^{13 \mathrm{~d}}$ A multinuclear species, presumably a trimer, was said to be involved and was said to be responsible for the observed diastereoselectivity.

In the present study, we extended our investigations to elucidate the reactivity of phenyl isocyanate and phenyl isothiocyanate towards mono and double insertion into titanium(IV) alkoxides. The mono and double insertion of phenyl isocyanate into the Ti-OR bond is calculated to be a facile process. However in the case of phenyl isothiocyanate only mono insertion appears to be favourable. The double insertion and the subsequent metathesis reaction of phenyl isothiocyanate is computed to be energetically unfavourable. Secondly, we carry out QM/MM calculations to compare the stability of multinuclear Ti-alkoxy species which are bridged and non-bridged. It is shown that the intermediate that best explains the observed diasteroselectivity is a trimeric alkoxy bridged species. Non-bridged forms and bridged dimeric species are predicted to result in loss of diasteroselectivity.

\section{Results and discussion}

\subsection{Comparison of insertion and metathesis reactivity of isocyanates and isothiocyanates catalysed by titanium (IV) alkoxides}

Earlier reports indicate that the insertion of titanium(IV) alkoxides and zirconium(IV) alkoxides into heterocumulenes are temperature dependent. ${ }^{12}$ Heterocumulenes such as isocyanates $\mathbf{2 0}$ undergo mono insertion and head-to-tail double insertion at room temperature. The mono and double insertion products are isolated as $3^{\prime} \mathbf{a O}$ and $\mathbf{4}^{\prime} \mathbf{a O}$ after hydrolysis (scheme 1). However, at higher temperatures $\left(110^{\circ} \mathrm{C}\right)$ in addition to mono insertion and head-to-tail double insertion products, head-to-head double insertion products are also

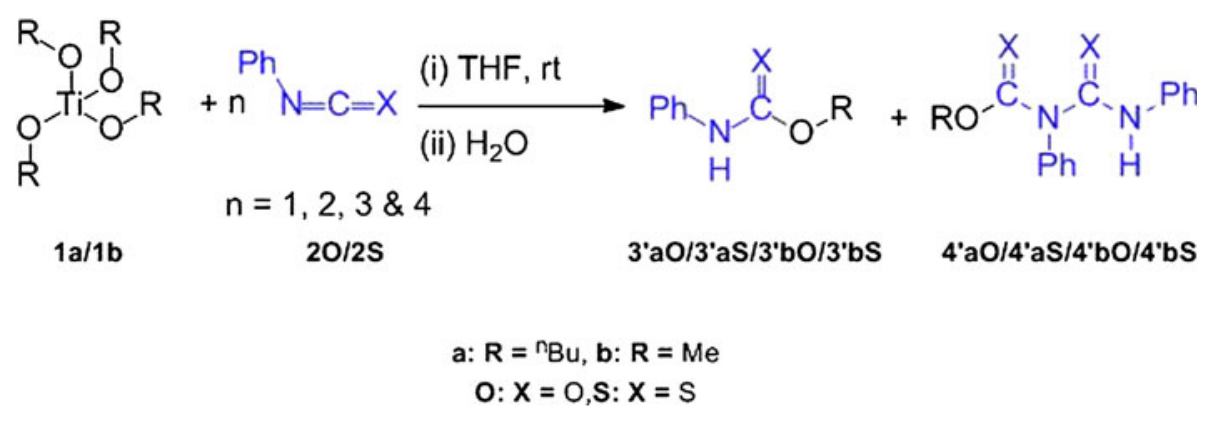

Scheme 1. Reaction of $\mathbf{2 0 / 2 S}$ with titanium(IV) alkoxides at room temperature leading to insertion products after aqueous work up. ${ }^{12}$ 


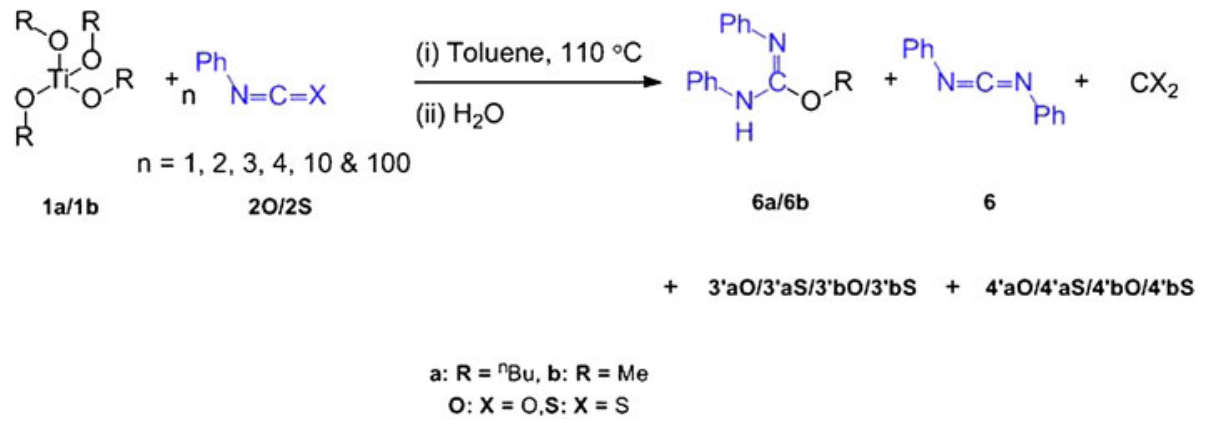

Scheme 2. Insertion-cum-metathesis products isolated after hydrolysis in the reaction of $\mathbf{2 0} / 2 \mathrm{~S}$ with titanium(IV) alkoxides at $110^{\circ} \mathrm{C} .^{12}$

observed. Such a double insertion of aryl isocyanate in a head-to-head fashion results in the elimination of carbon dioxide leading to metathesis. Stoichiometric reactions lead to isolation of metathesis-cum-insertion products 6a (scheme 2). The metathesis reaction are shown to be reversible; forming unsymmetrical carbodiimides when carried out with different aryl isocyanates. ${ }^{12 \mathrm{~b}, 12 \mathrm{~g}}$ It is also observed that steric factors slow down the metathesis reaction which is similar to the observation with insertion reactions. However, contrary to the substituent effects in insertion reactions, where electron withdrawing groups on the isocyanate favour the reaction, ${ }^{12 \mathrm{~b}, 12 \mathrm{~g}}$ metathesis reactions are favoured by electron donating groups. ${ }^{12 \mathrm{~b}, 12 \mathrm{e}, 12 \mathrm{~g}, 12 \mathrm{~h}}$ Similar to the reversal of electronic effects, the changes on moving from $\mathrm{Ti}$ to $\mathrm{Zr}$

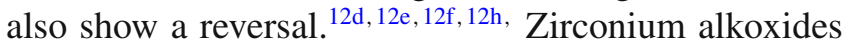
are shown to be better catalysts than titanium alkoxides for the metathesis reaction. ${ }^{12 \mathrm{f}}$

One expects similar reactions and reactivity patterns with isothiocyanates $\mathbf{2 S}$. Surprisingly, the reactivity pattern observed with aryl isothiocyanates is different. ${ }^{12}$ Only the mono insertion product $\mathbf{3}^{\prime} \mathbf{a S}$ is observed. The double insertion product $\mathbf{4}^{\prime} \mathbf{a S}$ is not formed. Even at elevated temperatures, the metathesis products $\mathbf{6 a}$ and 6 are not formed. It is postulated that the sulphur on the thiocarbamate $\mathbf{3 a S}$ (scheme 3 ) is not nucleophilic enough to attack the incoming isothiocyanate to form the six-membered intermediate 4aSHH or 4aSHT (scheme 4).
DFT calculations carried out at the (B3LYP/ LANL2DZ) level of theory are helpful in explaining why isothiocyanates fail to undergo head-to-tail and head-to-head double insertion. To reduce computational load, $\mathrm{Ti}\left(\mathrm{O}^{\mathrm{n}} \mathrm{Bu}\right)_{4}$ is modelled by $\mathrm{Ti}(\mathrm{OMe})_{4}$ where bulky $n$-butoxide groups are replaced by methoxide groups. The intermediates involved numbered and given codes depending on the "OR" group present (a: $\mathrm{R}={ }^{\mathrm{n}} \mathrm{Bu}, \mathbf{b}: \mathrm{R}=\mathrm{Me}$ ) and heterocumulene (PhNCX) employed ( $\mathbf{O}: \mathrm{X}=\mathrm{O}, \mathbf{S}: \mathrm{X}=\mathrm{S})$ in the reaction. For instance, the complex $\mathbf{4 a O H H}$ indicates structure $\mathbf{4}$ with $\mathrm{O}^{\mathrm{n}} \mathrm{Bu}$ as the alkoxy group and a structure where $\mathrm{PhNCO}$ has undergone double insertion in a head-tohead fashion. Similarly, 4bSHT indicates structure 4 with $\mathrm{OMe}$ as the alkoxy group and a structure where PhNCS has undergone double insertion in a head-to-tail fashion.

Titanium(IV) methoxide reacts with the first molecule of PhNCX (2O/2S) to generate the metal carbamate/thiocarbamate intermediate $\mathbf{3 b O} / \mathbf{3 b S}$. This reaction is computed to be more exothermic for PhNCO compared to PhNCS (scheme 3). However, the reaction of $\mathbf{2 S}$ with $\mathbf{1 b}$ is endothermic by only $3 \mathrm{kcal} / \mathrm{mol}$. This barrier may be not high enough to prevent the formation of $\mathbf{3 b S}$. Hence one would expect to observe mono insertion products of both $\mathbf{2 0}$ and 2S. This is in agreement with experimental results which show formation of both mono insertion products 3aO/3aS. ${ }^{12}$

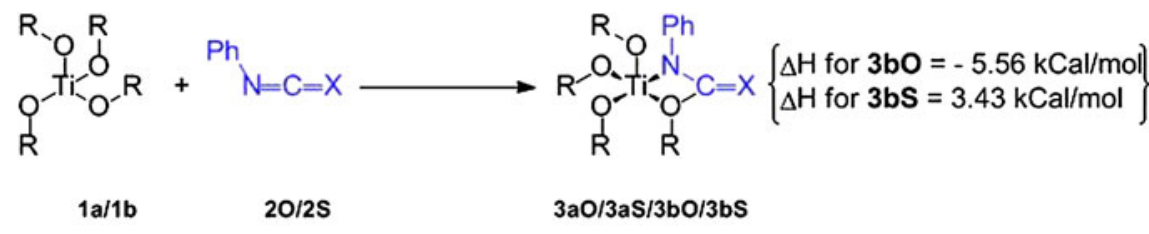

$$
\begin{gathered}
\text { a: } R={ }^{n B u}, b: R=M e \\
O: X=O, S: X=S
\end{gathered}
$$

Scheme 3. Insertion of $\mathbf{2 O} / \mathbf{2 S}$ into Ti-OR bond resulting in formation of metal carbamate $\mathrm{species} \mathbf{3 a O} / \mathbf{3 a S} / \mathbf{3 b O} / \mathbf{3 b S}$. 


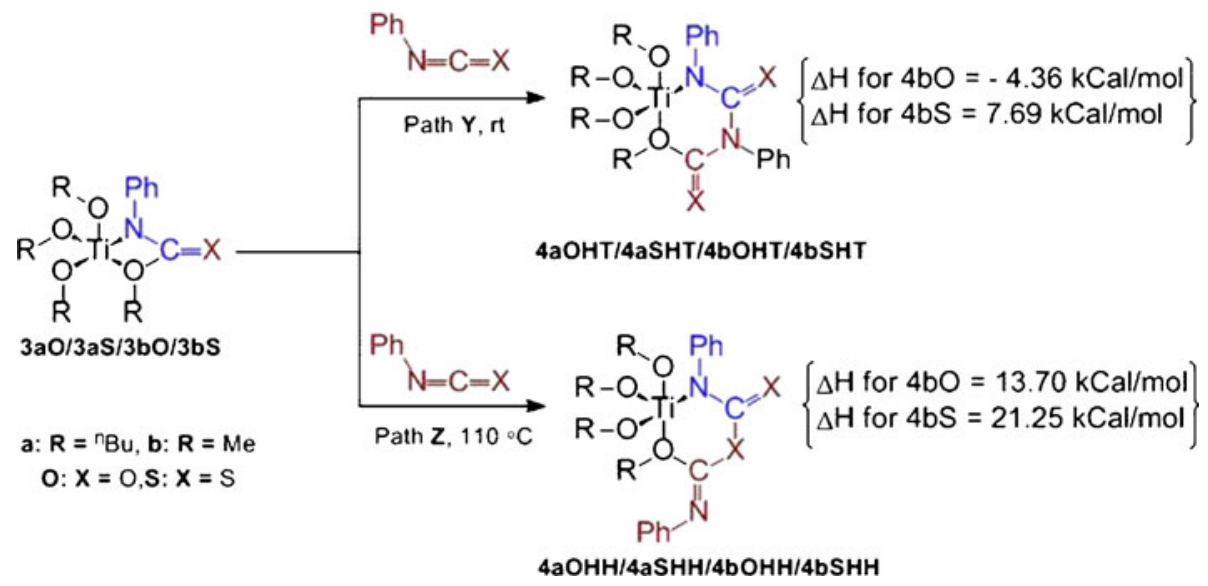

Scheme 4. Second insertion of $\mathbf{2 0} / \mathbf{2 S}$ into the metal carbamate species $3 \mathrm{aO} / 3 \mathrm{aS} /$ $\mathbf{3 b O} / \mathbf{3 b S}$ in a head-to-tail (path $\mathbf{Y}$ ) or head-to-head (path $\mathbf{Z}$ ) fashion.

Subsequent insertion of PhNCX (2O/2S) can take place either in a head-to-tail fashion giving 4bOHT/4bSHT (Path Y) or in a head-to-head fashion to give the intermediate $\mathbf{4 b O H H / 4 b S H H}$ (Path $\mathbf{Z}$ ) (scheme 4). Experimental results indicate that the double insertion proceeds only though Path $\mathbf{Y}$ at room temperature. Further, Path $\mathbf{Y}$ is observed only with phenyl isocyanate $\mathbf{2 O}$ and not with phenyl isothiocyanate $\mathbf{2 S}$. In a similar manner, at higher temperatures head-tohead insertion occurs in greater amounts through Path $\mathbf{Z}$ leading to metathesis. While 20 underwent this metathesis reaction, $\mathbf{2 S}$ failed to exhibit such a headto-head double insertion reaction. The reluctance of isothiocyanates to undergo double insertion either in a head-to-tail fashion or in a head-to-head fashion can be understood if one looks at the energetics of this reaction.

For $\mathrm{PhNCO}$, path $\mathbf{Y}$ is an exothermic process, whereas path $\mathbf{Z}$ is endothermic (scheme 4). This explains why head-to-head insertion is not observed at room temperature. For path $\mathbf{Y}$ it is seen that, the formation of $\mathbf{4 b O H T}$ is an exothermic process. Hence the head-to-tail double insertion occurs readily and the intermediate 4aOHT leads to the isolation of $\mathbf{4}^{\prime} \mathbf{a O}$ after hydrolysis. On the other hand, the formation of 4bSHT from $3 \mathrm{bS}$ is calculated to be highly endothermic. The intermediate 4bSHT is destabilized by about $12 \mathrm{kcal} / \mathrm{mol}$ compared to $\mathbf{1 b}+\mathbf{2} \mathbf{S}$ (figure 1 ). Hence the double insertion in a head-to-tail mode occurs only with $2 \mathrm{O}$ and not with $\mathbf{2 S}$.

Path $\mathbf{Z}$ is endothermic for both $\mathbf{2 O}$ and $\mathbf{2 S}$, however the formation of $\mathbf{4 b O H H}$ is less endothermic. The reaction of $\mathbf{3 b S}$ with $\mathbf{2 S}$ in a head-to-head fashion leading to $\mathbf{4 b S H H}$ appears to be a highly unfavourable process. The species $\mathbf{4 b S H H}$ is destabilized by $24 \mathrm{kcal} / \mathrm{mol}$ compared to the alkoxide $\mathbf{1 b}$. It is likely that this energy is high enough to hinder the formation of $\mathbf{4 b S H H}$. This renders the second insertion of $\mathbf{2 S}$ into $\mathbf{3 b S}$ in a headto-head mode unfavourable. This argument is consistent with experimental results where $\mathbf{2} \mathbf{S}$ does not lead to metathesis products $\mathbf{6 a} / \mathbf{6}$.

The extrusion of carbon dioxide from $\mathbf{4 b O H H}$ to give the carbodiimide inserted intermediate $\mathbf{5 b}$ is less exothermic compared to the extrusion of carbon disulphide from $\mathbf{4 b S H H}$ to give $\mathbf{5 b}$ (scheme 5, figure 2). Hence it is likely that it is the previous step, $\mathbf{3 b S} \rightarrow$ $\mathbf{4 b S H H}$, that has a detrimental effect on the metathesis of $2 \mathrm{~S}$.

One could assume that the reverse reaction involving the metathesis of carbon dioxide/carbon disulphide with carabodiimide 6 to give the isocyanate 2O/2S via the intermediate $\mathbf{4 b O H H} / \mathbf{4 b S H H}$ follows the same path. In this case, the process $\mathbf{5 b} \rightarrow \mathbf{4 b S H H}$ is energetically

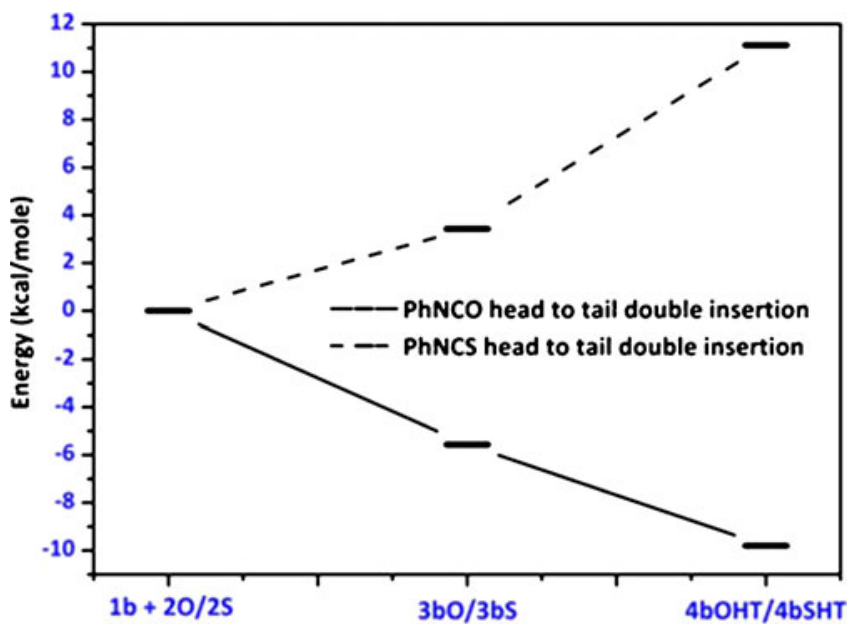

Figure 1. Computed energy profile for the sequential insertion of $\mathbf{2 O} / \mathbf{2 S}$ into $\mathrm{Ti}(\mathrm{OMe})_{4}$ through path $\mathbf{Y}$ done at the B3LYP/LANL2DZ level of theory. 


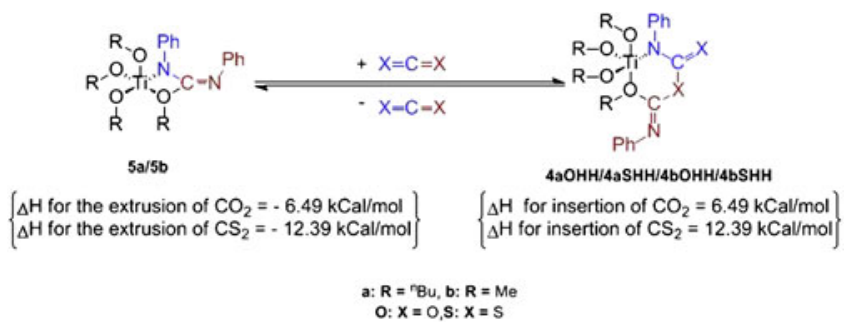

Scheme 5. Reversible extrusion of $\mathrm{CO}_{2} / \mathrm{CS}_{2}$ from 4aOHH/4aSHH/4bOHH/4bSHH.

more costly compared to $\mathbf{5 b} \rightarrow \mathbf{4 b O H H}$ (scheme 5 , figure 2). Hence, the metathesis of carbon dioxide is also better than the metathesis of carbon disulphide. Not surprisingly, this is confirmed by experimental results where carbon disulphide fails to undergo a metathesis reaction with carbodiimide. The steps involved in the catalytic cycle are given in scheme 6 . The overall energy changes associated with this catalytic reaction is depicted in figure 2 . Thus, the computed thermodynamic stabilities of intermediates provide useful insights into the contrasting preferences of $\mathrm{PhNCO}$ and PhNCS towards double insertion and subsequent extrusion of carbon dioxide and carbon disulphide, respectively.

\subsection{Comparison of the stability of bridged and} non-bridged intermediates generated by the reaction of LVT titanium alkoxides and imines

When treated with reducing agents such as Grignard reagents or phenylsilane, titanium(IV) alkoxides generate low-valent titanium species (LVT). ${ }^{13 \mathrm{c}, 13 \mathrm{~d}}$ The LVT species can be either Ti(II) speicies, such as 7, or Ti(III)

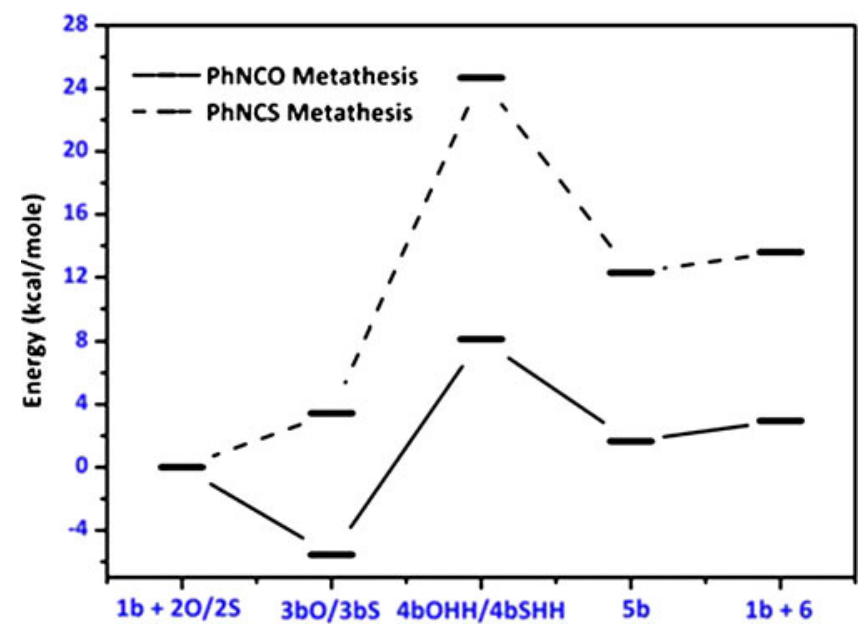

Figure 2. Computed energy profile for the sequential insertion of $\mathbf{2 O} / \mathbf{2 S}$ into $\mathrm{Ti}(\mathrm{OMe})_{4}$ through path $\mathbf{Z}$ estimated at the B3LYP/LANL2DZ level of theory.

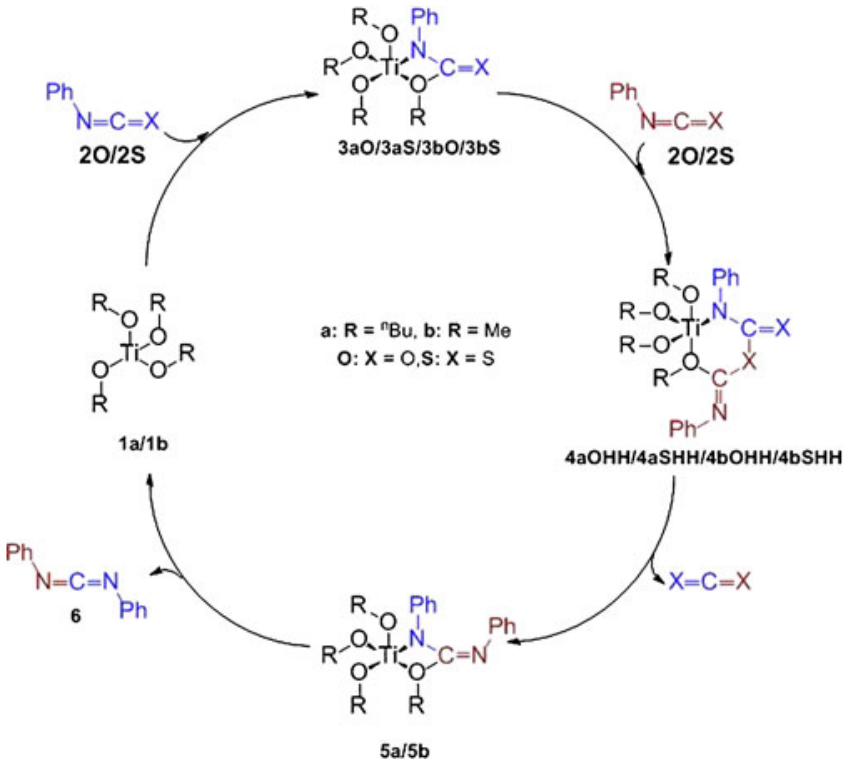

Scheme 6. Intermediates involved in the plausible metathesis of $\mathbf{2 0 / 2 S}$ mediated by titanium(IV) alkoxide.

species, such as $\mathbf{8}$ (shown in scheme 7). Species $\mathbf{7}$ can form dimers such as $\mathbf{9}$ and $\mathbf{9 B}$.

Reduction of the imine by these species leads subsequently to an amine $\mathbf{1 2}$ or coupling of the imine can produce diammines $\mathbf{1 3}$ (scheme 8). ${ }^{13}$ Although reduction and coupling of imines occurred with both reducing agents, the coupling of imines is diastereoselective when phenylsilane is used as a reducing agent. This suggests that the nature of the LVT species formed with a Grignard and the intermediate generated with the imine is different from what is formed with phenylsilane.

The diastereoselective products obtained in the case of reactions with phenylsilane, increased with the concentration of titanium(IV) isopropoxide used. This clearly rules out the possibility of an unimolecular $\mathrm{Ti}$ species as an intermediate in the coupling reaction. The species that is likely to be involved is either a Ti(III) species like $\mathbf{8}$ or a trimeric biradical species such as 9 which can reduce the imine. Mass spectral studies showed the possible involvement of a trimeric biradical species experimentally. But it is difficult to arrive at the actual structure of the species involved in the reaction from mass spectral data. To understand the observed diastereoselectivity in the $\mathrm{C}-\mathrm{C}$ coupling reaction, the possible intermediates involved in the $\mathrm{C}-\mathrm{C}$ bond formation are modelled computationally. It is possible that the isopropoxide ligands have some influence on the observed selectivity, though these groups are not directly involved in the reaction. Hence instead of simplifying the system by replacing the ${ }^{i} \mathrm{Pr}$ groups on $\mathrm{Ti}$ 

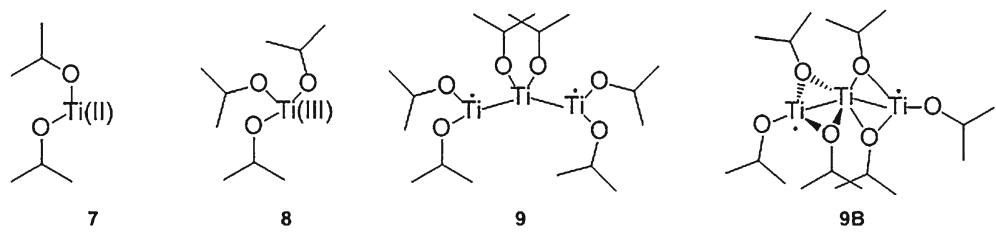

Scheme 7. Possible LVT species generated by the reaction of titanium(IV) isopropoxide with reducing agents.
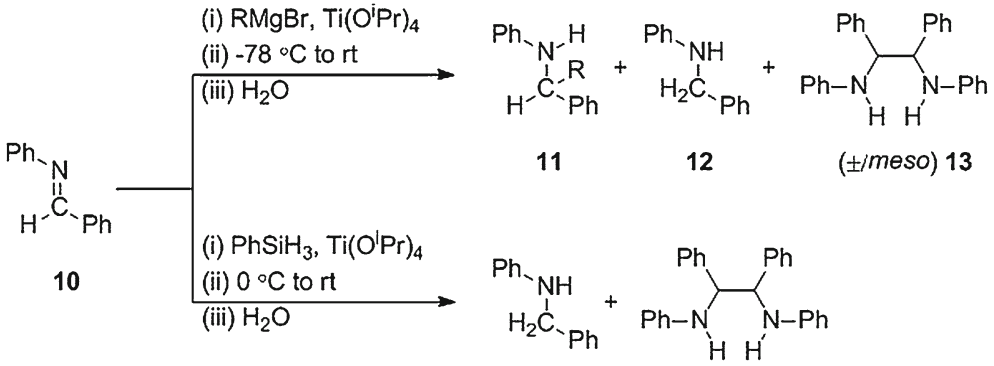

12

(士) 13

Scheme 8. Reductive reactions of imine mediated by LVT generated from Grignard and phenylsilane.<smiles>CC(C)O[Al]OC(C)C</smiles><smiles>C=C(c1ccccc1)c1ccccn1</smiles>

10<smiles>CC(C)O[P+](OC1OC(C)CC1C)(N(c1ccccc1)c1ccccc1)N(c1ccccc1)c1ccccc1</smiles>

14

Scheme 9. $\mathrm{Ti}^{\mathrm{IV}}$ Intermediate $\mathbf{1 4}$ formed in the reaction of low valent titanium species $\mathbf{8}$ with imine $\mathbf{1 0}$.<smiles>CC(C)OP(OC(C)C)[In]1C2CC(C)C(O2)P1[Te](OC(C)C)OC(C)C</smiles>

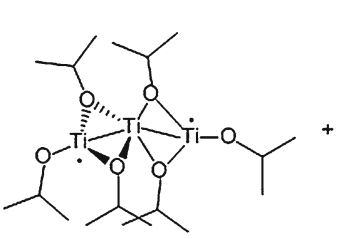

$9 B$

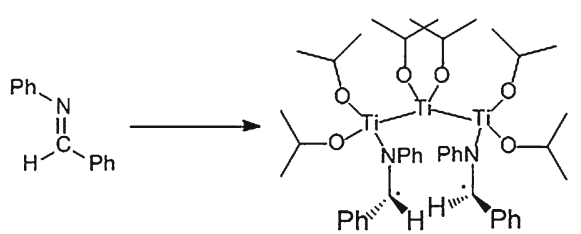

10

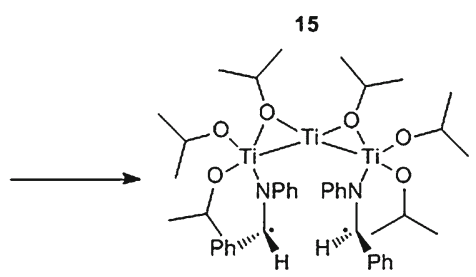

$15 B$

Scheme 10. Formation of trimeric Ti species 15/15B. 


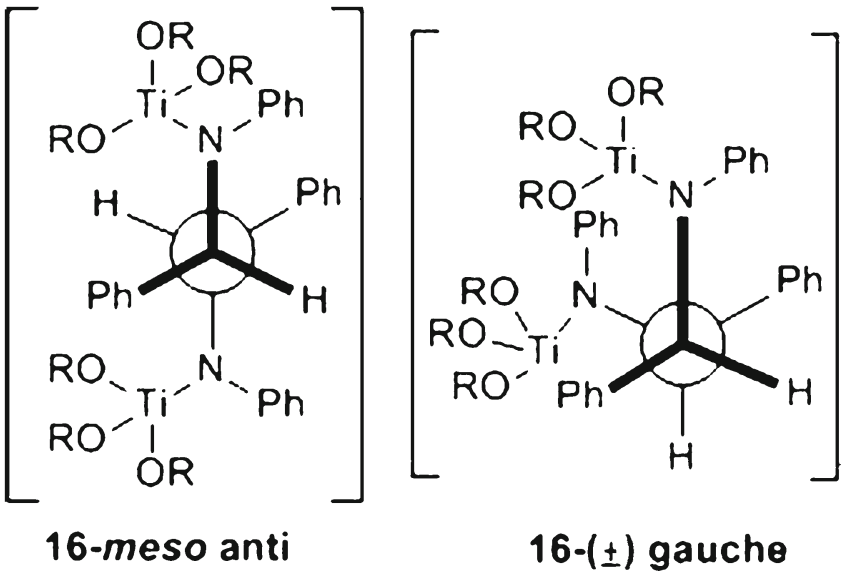

Scheme 11. The most favourable conformers of $\mathbf{1 6}( \pm)$ and 16 meso.

by OMe groups, we use a QM/MM approach to evaluate the relative stabilities of the two diastereomers. In this method the $\mathrm{Ti}$ atoms, $\mathrm{N}$ atoms, $\mathrm{O}$ atoms and $\mathrm{C}$ atoms (those involved in $\mathrm{C}-\mathrm{C}$ coupling and the methine carbon on isopropoxide) are considered as the high layer and treated quantum mechanically. A molecular mechanics calculation is performed on the rest of the system to understand the steric effects of the isopropoxide which is defined as the low layer.

Calculations were carried out to compare the relative stabilities of alkoxy bridged trimeric biradical species 9B with its non-bridged form 9. These studies reveal that bridged form $9 \mathrm{~B}$ is more stable than the non-bridged form 9 by about $30 \mathrm{kcal} / \mathrm{mol}$. During the reductive coupling, if the imine $\mathbf{1 0}$ reacts with a $\mathrm{Ti}^{\mathrm{III}}$ species $\mathbf{8}$, then it would lead to the formation of a $\mathrm{Ti}^{\mathrm{IV}}$ species 14 (scheme 9). The trimeric biradical species 9/9B could react with imines to give the trimeric species 15/15B (scheme 10). All intermediates (15/15B and 14) could lead to the coupled product 13.

Two molecules of the $\mathrm{Ti}^{\mathrm{IV}}$ intermediate $\mathbf{1 4}$ are combined to give the $\mathrm{C}-\mathrm{C}$ coupled $\mathrm{Ti}^{\mathrm{IV}}$ intermediates, 16$( \pm$ ) or 16-meso (scheme 11). The alkoxy bridged forms

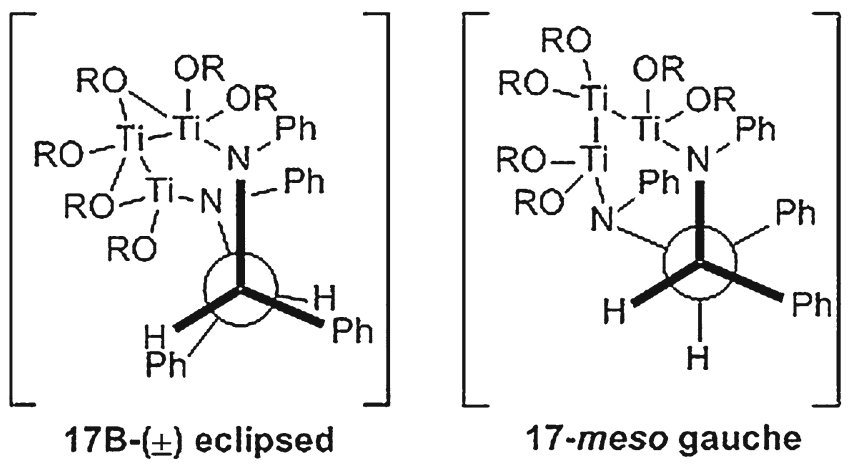

Scheme 12. The most favourable conformations formed of $17( \pm)$ and $\mathbf{1 7}$ meso.

16B- $( \pm)$ gauche/16B-meso gauche are also optimized and their relative energy estimated. All conformers, gauche, anti and eclipsed forms of the two isomers are examined. The relative energies of all the optimized conformers, with and without alkoxy bridges, resulting from the bimolecular interaction of $\mathbf{1 4}$ are summarized in table 1 . Based on the very low energy difference between 16- $( \pm)$ gauche and 16-meso anti one might conclude that both $( \pm)$ and the meso isomers would be formed in nearly equal amounts. ${ }^{13 \mathrm{~d}}$ It is interesting to note that the bimolecular intermediate that involves alkoxy bridges is destabilized relative to the dinuclear species with out a bridge. The bridged meso isomer 16B-meso gauche is destabilized by about $17 \mathrm{kcal} / \mathrm{mol}$ compared to the most favourable non-bridged meso isomer 16-meso anti (entries 7 and 8 , table 1). Similarly, the formation of the bridged $( \pm)$ isomer 16B- $( \pm)$ gauche is unfavourable by about $28 \mathrm{kcal} / \mathrm{mol}$ relative to its most stable non-bridged form 16- $( \pm)$ gauche (entries 2, 3 and 9, table 1). Since experimental results show the exclusive formation of $( \pm)$ isomer, it is unlikely that intermediate $\mathbf{1 6}$ is involved in the reaction. ${ }^{13 \mathrm{~d}}$

If one considers a species such as $\mathbf{1 5}$, which does not contain an alkoxy bridge, the coupling would lead

Table 1. Relative energies of optimized conformers of $\mathbf{1 6}$ with and without alkoxy bridges.

\begin{tabular}{|c|c|c|c|}
\hline Entry & Initial conformation & Optimized conformation & Energy $(\mathrm{kcal} / \mathrm{mol})$ \\
\hline 1 & 16- $( \pm)$ eclipsed (Dihedral angle $\left.=0^{\circ}\right)$ & 16- $( \pm)$ eclipsed $\left(\right.$ Dihedral angle $\left.=2^{\circ}\right)$ & 17.7 \\
\hline 2 & 16- $( \pm)$ gauche $\left(\right.$ Dihedral angle $\left.=60^{\circ}\right)$ & 16- $( \pm)$ gauche $\left(\right.$ Dihedral angle $\left.=70^{\circ}\right)$ & 0.0 \\
\hline 3 & 16- $( \pm)$ gauche $^{\prime}\left(\right.$ Dihedral angle $\left.=120^{\circ}\right)$ & 16- $( \pm)$ gauche $\left(\right.$ Dihedral angle $\left.=70^{\circ}\right)$ & 0.0 \\
\hline 4 & 16- $( \pm)$ anti $\left(\right.$ Dihedral angle $\left.=180^{\circ}\right)$ & 16- $( \pm)$ anti $\left(\right.$ Dihedral angle $\left.=180^{\circ}\right)$ & 5.1 \\
\hline 5 & 16- meso eclipsed (Dihedral angle $=0^{\circ}$ ) & 16- meso gauche $\left(\right.$ Dihedral angle $\left.=60^{\circ}\right)$ & 10.0 \\
\hline 6 & 16- meso gauche $\left(\right.$ Dihedral angle $\left.=120^{\circ}\right)$ & 16- meso gauche $\left(\right.$ Dihedral angle $\left.=90^{\circ}\right)$ & 6.8 \\
\hline 7 & 16- meso anti $\left(\right.$ Dihedral angle $\left.=180^{\circ}\right)$ & 16- meso anti $\left(\right.$ Dihedral angle $\left.=180^{\circ}\right)$ & 2.1 \\
\hline 8 & 16B- meso eclipsed (Dihedral angle $=0^{\circ}$ ) & 16B- meso gauche $\left(\right.$ Dihedral angle $\left.=76^{\circ}\right)$ & 19.0 \\
\hline 9 & 16B-( $( \pm)$ eclipsed $\left(\right.$ Dihedral angle $\left.=0^{\circ}\right)$ & 16B- $( \pm)$ gauche $\left(\right.$ Dihedral angle $\left.=68^{\circ}\right)$ & 27.9 \\
\hline
\end{tabular}


Table 2. Relative energies of optimized conformers $\mathbf{1 7}$ with and without alkoxy bridges.

\begin{tabular}{|c|c|c|c|}
\hline Entry & Initial conformation & Optimized conformation & Energy $(\mathrm{kcal} / \mathrm{mol})$ \\
\hline 1 & 17- $( \pm)$ eclipsed (Dihedral angle $=0^{\circ}$ ) & 17- $( \pm)$ gauche $\left(\right.$ Dihedral angle $\left.=49^{\circ}\right)$ & 13.4 \\
\hline 2 & 17- meso eclipsed (Dihedral angle $=0^{\circ}$ ) & 17- meso gauche (Dihedral angle $=51^{\circ}$ ) & 17.0 \\
\hline 3 & 17B- $\left( \pm\right.$ ) eclipsed (Dihedral angle $=0^{\circ}$ ) & 17B- $( \pm)$ eclipsed $\left(\right.$ Dihedral angle $\left.=17^{\circ}\right)$ & 0.0 \\
\hline 4 & 17B- $\left( \pm\right.$ ) gauche $\left(\right.$ Dihedral angle $\left.=60^{\circ}\right)$ & 17B- $\left( \pm\right.$ ) gauche $\left(\right.$ Dihedral angle $\left.=27^{\circ}\right)$ & 29.9 \\
\hline 5 & 17B- meso eclipsed (Dihedral angle $=0^{\circ}$ ) & 17B- meso gauche (Dihedral angle $=50^{\circ}$ ) & 41 \\
\hline
\end{tabular}

to the multinuclear intermediates 17- $( \pm)$ gauche or 17meso gauche. On the contrary, intermediate 15B which contains two alkoxy bridges, gives 17B- $( \pm)$ eclipsed or 17B-meso gauche (scheme 12). Due to the cyclic form of the intermediate $(\mathbf{1 5} / \mathbf{1 5 B})$, only eclipsed and gauche conformations are possible. We now compare the stability of various conformations of intermediate 17 with and without alkoxy bridges (table 2). Unlike the dinuclear intermediates discussed above, the formation of alkoxy bridged $( \pm)$ isomer 17B- $( \pm)$ eclipsed is favoured by about $13 \mathrm{kcal} / \mathrm{mol}$ compared to its nonbridged isomer 17- $( \pm)$ gauche (entries 1 and 3, table 2). Surprisingly in the case of the meso isomer, the non-bridged form, 17-meso gauche is stabilized by $25 \mathrm{kcal} / \mathrm{mol}$ relative to the alkoxy bridged isomer 17Bmeso gauche (entries 2 and 5, table 2). Thus, the alkoxy bridged forms are favoured in the intermediates leading to the formation of the $( \pm)$ coupled product, whereas the favoured meso coupling involves non-bridged intermediates. Thus, the most stable conformer 17B- $( \pm)$ eclipsed (entry 3 , table 2 ) is the one that leads to $( \pm$ ) diastereoselectivity. This is completely in accordance with experimental results.

Thus, hybrid computational methods are useful in determining the nature of intermediates in the reactions of large molecules. In this case, it would not have been possible to distinguish the two paths without recourse to computational methods. Not only do they allow us to distinguish between the dimeric and trimeric intermediates, they also throw light on the bridging nature of alkoxides in these species.

\section{Computational details}

\subsection{Comparison of insertion and metathesis} reactivity of isocyanates and isothiocyanates catalysed by titanium (IV) alkoxides

For theoretical studies, $\mathrm{Ti}(\mathrm{OMe})_{4}$ and $\mathrm{Zr}(\mathrm{OMe})_{4}$ are taken as model complexes in place of $\mathrm{Ti}\left(\mathrm{O}^{\mathrm{n}} \mathrm{Bu}\right)_{4}$ and $\mathrm{Zr}\left(\mathrm{O}^{\mathrm{n}} \mathrm{Bu}\right)_{4}$ where bulky ${ }^{\mathrm{n}} \mathrm{Bu}$ groups are replaced by $\mathrm{Me}$ groups for computational efficiency. All structures are optimized using the DFT method (B3LYP/LANL2DZ), based on Becke's three-parameter functional. ${ }^{14}$ The LANL2DZ basis set uses the effective core potentials (ECP) of Hay and Wadt. ${ }^{15}$ The nature of the stationary points is characterized by vibrational frequency calculations. The Gaussian 03 program package is used for all calculations. ${ }^{16}$

\subsection{Comparison of stability of bridged and}

non-bridged intermediates generated by the reaction of LVT titanium alkoxides and imines

The imine 10, titanium intermediates $\mathbf{8 , 9}, 16$ and 17 are modelled. All structures are optimized using the multilayer ONIOM model was used where the $\mathrm{Ti}$ atoms, $\mathrm{N}$ atoms, $\mathrm{O}$ atoms and $\mathrm{C}$ atoms (involved in $\mathrm{C}-\mathrm{C}$ coupling and methine carbon on isopropoxide) are considered as the high layer and the rest of the atoms are defined as a low layer. The high layer was optimized using DFT at the B3LYP/LANL2DZ level of theory and the low layer was optimized using molecular mechanics calculation with the UFF forcefield. The Gaussian 09 program package was used for all multilayer ONIOM calculations. ${ }^{17}$

\section{Conclusion}

Computational studies carried out at the B3LYP/ LANL2DZ level on model metal alkoxides are helpful in understanding the reactivity pattern and the reaction path. There are distinct differences in the reactivity of $\mathrm{PhNCO}$ and PhNCS towards metathesis. While $\mathrm{PhNCO}$ undergoes mono insertion and double insertion either in a head-to-tail or head-to-head fashion, PhNCS exhibits only mono insertion and no double insertion. Calculations attribute this difference to the energetics of the reaction. Double insertion of PhNCO into titanium(IV) alkoxides is highly favourable. On the other hand, this reaction is calculated to be an energetically costly process for PhNCS. This renders PhNCS inactive towards double insertion and subsequent metathesis reactions. Due to similar reasons, the metathesis of carbon disulphide and carbodiimides fails to occur. 
Multilayer ONIOM calculations are used to investigate the relative stabilities of multinuclear Ti intermediates that are involved in the diastereoselective coupling of imines. Although, earlier studies show that reduction of imines by a trimeric biradical species is responsible for the selectivity, it is not clear if the intermediates involve a bridged species. Careful examination of the energies of the intermediates involved in the reaction reveal the importance of alkoxy bridged multinuclear species in achieving diastereoselective coupling. It is important to note that one of the precursors based on the trimeric biradical is stabilized to a great extent by the presence of alkoxy bridges. Calculations show that the non-bridged forms are favoured in the dinuclear intermediates! Again, this is a counter intuitive result as one would think alkoxy bridges are important in all multinuclear Ti species. Moreover, this binuclear interaction is likely to result in a mixture of both diastereomers. Alkoxy bridging is only important in the trimeric species where $( \pm)$ coupling is favoured. Given the fact that there is an exclusive formation of $( \pm)$ isomers experimentally, these calculations strongly indicate the involvement of intermediates like 17/17B in the reaction. Once again, we find that computational tools are useful in determining the reaction pathway involving titanium-isopropoxide complexes.

\section{Acknowledgements}

AGS thanks the Department of Science and Technology (DST), New Delhi for the award of a research grant and AK gratefully acknowledges for Post Doctoral Fellowship from Indian Institute of Science (IISc), Bangalore. Authors also thank Prof. ED Jemmis, Dr. $S$ De and Dr. S Dinda and M Thenraj for their help and suggestions. Thanks are also due to Supercomputer Education and Research Centre (SERC) of IISc for computational facilities.

\section{Supplementary information}

The supplementary information can be seen in www.ias.ac.in/chemsci.

\section{References}

1. (a) Carter E A and Rossky E J 2006 Acc. Chem. Res. 39 71; (b) Lin Z 2010 Acc. Chem. Res. 43 602; (c) Schröder D, Shaik S and Schwarz H 2000 Acc. Chem. Res. 33 139; (d) Scuseria G E 1999 J. Phys. Chem. A 103 4782; (e) Maseras F and Morokuma K 1995 J. Comput. Chem. 16 1170; (f) Svensson M, Humbel S, Froese R D J, Matsubara T, Sieber S and Morokuma K 1996 J. Phys.
Chem. 100 19357; (g) Dapprich S, Komaromi I, Byun K S, Morokuma K, Frisch M J 1999 J. Mol. Struct.: THEOCHEM 461-462 1

2. (a) Davidson E R 2000 Chem. Rev. 100 351; (b) Bruice T C 2006 Chem. Rev. 106 3119; (c) Balcells D, Clot E and Eisenstein O 2010 Chem. Rev. 110 749; (d) Bifulco G, Dambruoso P, Gomez-Paloma L and Riccio R 2007 Chem. Rev. 107 3744; (e) Proft F D and Geerlings P 2001 Chem. Rev. 101 1451; (f) Kraka E and Cremer D 2010 Acc. Chem. Res. 43 591; (g) Zhao Y and Truhlar D G 2008 Acc. Chem. Res. 41157

3. (a) Schwabe $\mathrm{T}$ and Grimme S 2008 Acc. Chem. Res. 41 569; (b) Clementi E, Corongiu G, Bahattacharya D, Feuston B, Frye D, Preiskorn A, Rizzo A and Xue W 1991 Chem. Rev. 91 679; (c) Karadakov P B 2001 Annu. Rep. Prog. Chem. Sect. C 9761

4. (a) Morokuma K 2007 Bull. Chem. Soc. Jpn. 80 2247; (b) Piyaauksornsak S, Tangthongkul T, Wanbayor R, Wanno B and Ruangpornvisuti V 2009 Struct. Chem. 20 767; (c) Ananikov V P, Musaev D G and Morokuma K 2010 J. Mol. Catal. A: Chem. 324104

5. (a) Bo C and Maseras F 2008 Dalton Trans. 2911; (b) Basiuk V A and Basiuk E V 2004 Nanotechnology 2395

6. (a) Svelle S, Visur M, Olsbye U, Saepurahman and Bjørgen M 2011 Top Catal. 54 897; (b) North M, Usanov D L and Young C 2008 Chem. Rev. 108 5146; (c) Bakalova S M and Kaneti J 2008 J. Phys. Chem. A 112 13006; (d) Dudding T and Houk K N 2004 Proc. Natl. Acad. Sci. USA 101 5770; (e) Cantillo D, Avalos M, Babiano R, Cintas P, Jimenez J L and Palacios J C 2011 Org. Biomol. Chem. 9 7638; (f) Ishikawa A, Nakao Y, Sato H and Sakaki S 2010 Dalton Trans. 3279; (g) Cowley R E, Eckert N A, Vaddadi S, Figg T M, Cundari T R and Holland P L $2011 \mathrm{~J}$. Am. Chem. Soc. 133 9796; (h) Wang C-M, Wang Y-D, Liu H-X, Xie Z-K and Liu Z-P 2010 J. Catal. 271386

7. (a) Pavan Kumar P N V and Jemmis E D 1988 J. Am. Chem. Soc. 110 125; (b) Jemmis E D and Giju K T 1997 Angew. Chem. Int. Ed. Engl. 36606

8. (a) Jemmis E D and Giju K T 1998 J. Am. Chem. Soc. 120 6952; (b) Jemmis E D, Phukan A K and Giju K T 2002 Organometallics 212254

9. Kaleta K, Ruhmann M, Theilmann O, Beweries T, Roy S, Arndt P, Villinger A, Jemmis E D, Schulz A and Rosenthal U 2011 J. Am. Chem. Soc. 1335463

10. (a) Schofield A D, Nova A, Selby J D, Schwarz A D, Clot E and Mountford P 2011 Chem. Eur. J. 17 265; (b) Tiong P J, Nova A, Groom L R, Schwarz A D, Selby J D, Schofield A D, Clot E and Mountford P 2011 Organometallics 30 1182-1201; (c) Schofield A D, Nova A, Selby J D, Manley C D, Schwarz A D, Clot E and Mountford P 2010 J. Am. Chem. Soc. 132 10484; (d) Tiong P-J, Schofield A D, Selby J D, Nova A, Clot E and Mountford P 2010 Chem. Commun. 46 85; (e) Selby J D, Schulten C, Schwarz A D, Stasch A, Clot E, Jones C and Mountford P 2008 Chem. Commun. 5101

11. (a) Guiducci A E, Boyd C L, Clot E and Mountford P 2009 Dalton Trans. 5960; (b) Bolton P D, Feliz M, Cowley A R, Clot E and Mountford P 2008 Organometallics 276096

12. (a) Ghosh R, Nethaji M and Samuelson A G 2005 J. Organomet. Chem. 690 1282; (b) Ghosh R and Samuelson A G 2005 Chem. Commun. 115 2017; (c) 
Ghosh R, Nethaji M and Samuelson A G 2003 Chem. Commun. 113 2556; (d) Kumar A, De S, Samuelson A G and Jemmis E D 2008 Organometallics 27 955; (e) Kumar A and Samuelson A G 2010 J. Organomet. Chem. 695 338; (f) Kumar A and Samuelson A G 2011 J. Chem. Sci. 123 29; (g) Ghosh R 2004 Ph. D Thesis Indian Institute of Science; (h) Kumar A 2009 Ph. D Thesis, Indian Institute of Science

13. (a) Qin S, Hu C, Yang $\mathrm{H}$ and $\mathrm{Su} \mathrm{Z} 2008$ J. Org. Chem. 73 4840; (b) Martínez S, Ramos J, Cruz V L and Martínez-Salazar J 2006 Polymer 47 883; (c) Kumar A and Samuelson A G 2010 Chem. Asian J. 5 1830; (d) Kumar A and Samuelson A G 2011 Eur. J. Org. Chem. 951

14. (a) Becke A D 1993 J. Chem. Phys. 98 5648; (b) Becke A D 1988 Phys. Rev. A 38 3098; (c) Lee C, Yang W and Parr R G 1988 Phys. Rev. B 37785

15. (a) Hay P J and Wadt W R 1985 J. Chem. Phys. 82 270;

(b) Wadt W R and Hay P J 1985 J. Chem. Phys. 82 284;

(c) Hay P J and Wadt W R 1985 J. Chem. Phys. 82299

16. Gaussian 03, Revision C.02, Frisch M J, Trucks G W, Schlegel H B, Scuseria G E, Robb M A, Cheeseman J R, Montgomery Jr. J A, Vreven T, Kudin K N, Burant J C, Millam J M, Iyengar S S, Tomasi J, Barone V, Mennucci B, Cossi M, Scalmani G, Rega N, Petersson G A, Nakatsuji H, Hada M, Ehara M, Toyota K, Fukuda R, Hasegawa J, Ishida M, Nakajima T, Honda Y, Kitao O, Nakai H, Klene M, Li X, Knox J E, Hratchian H P, Cross J B, Bakken V, Adamo C, Jaramillo J, Gomperts R, Stratmann R E, Yazyev O, Austin A J,
Cammi R, Pomelli C, Ochterski J W, Ayala P Y, Morokuma K, Voth G A, Salvador P, Dannenberg J J, Zakrzewski V G, Dapprich S, Daniels A D, Strain M C, Farkas O, Malick D K, Rabuck A D, Raghavachari K, Foresman J B, Ortiz J V, Cui Q, Baboul A G, Clifford S, Cioslowski J, Stefanov B B, Liu G, Liashenko A, Piskorz P, Komaromi I, Martin R L, Fox D J, Keith T, Al Laham M A, Peng C Y, Nanayakkara A, Challacombe M, Gill P M W, Johnson B, Chen W, Wong M W, Gonzalez C and Pople J A 2004 Wallingford CT: Gaussian, Inc

17. Frisch M J, Trucks G W, Schlegel H B, Scuseria G E, Robb M A, Cheeseman J R, Scalmani G, Barone V, Mennucci B, Petersson G A, Nakatsuji H, Caricato M, Li X, Hratchian H P, Izmaylov A F, Bloino J Zheng G, Sonnenberg J L, Hada M, Ehara M, Toyota K, Fukuda R, Hasegawa J, Ishida M, Nakajima T, Honda Y, Kitao $\mathrm{O}$, Nakai H, Vreven T, Montgomery J A, Peralta Jr, J E, Ogliaro F, Bearpark M, Heyd J J, Brothers E, Kudin K N, Staroverov V N, Kobayashi R, Normand J, Raghavachari K, Rendell A, Burant J C, Iyengar S S, Tomasi J, Cossi M, Rega N, Millam J M, Klene M, Knox J E, Cross J B, Bakken V, Adamo C, Jaramillo J, Gomperts R, Stratmann R E, Yazyev O, Austin A J, Cammi R, Pomelli C, Ochterski J W, Martin R L, Morokuma K, Zakrzewski V G, Voth G A, Salvador P, Dannenberg J J, Dapprich S, Daniels A D, Farkas O, Foresman J B, Ortiz J V, Cioslowski J and Fox D J 2009 Gaussian 09, Revision A.02, Wallingford CT: Gaussian, Inc 